\title{
JUVENTUDE E ESCOLA: VIOLÊNCIA E PRINCÍPIOS DE JUSTIÇA EM ESCOLARES DE ENSINO MÉDIO
}

\author{
YOUTH AND SCHOOL: VIOLENCE AND \\ PRINCIPLES OF JUSTICE IN HIGH \\ SCHOOL STUDENTS
}

\author{
Alice Miriam Happ Botler ${ }^{1, *}$
}

\begin{abstract}
RESUMO: O artigo analisa as percepções de justiça e injustiça no espaço escolar, com ênfase nos princípios de justiça. A pesquisa com escolares do Ensino Médio de Brasil e Portugal contrasta o sentimento de injustiça resultante de conflitos presentes nas duas realidades. Apoia-se em conceitos como juventudes, democracia e justiça. Os dados tratados via análise de conteúdo reforçam a tese de que a escola é um lugar propício para resolver conflitos de maneira não violenta, e acrescenta como seus limites a fundamentação nos princípios básicos da justiça: a comunicação não violenta, a empatia e o respeito.
\end{abstract}

Palavras-chave: Juventude. Escola. Justiça. Democracia. Violência.

\begin{abstract}
The article analyzes the perceptions of justice and injustice in the school space, with emphasis on the principles of justice. The research with High School students from Brazil and Portugal contrasts the feeling of injustice resulting from all sorts of conflicts present in both realities. It is based on concepts such as youth, democracy, and justice. The data, treated by content analysis, reinforces the thesis that the school is a propitious place to resolve conflicts in a nonviolent way, and adds, as its limits, the foundations of the basic principles of justice, such as nonviolent communication, empathy, and respect.
\end{abstract}

Keywords: Youth. School. Justice. Democracy. Violence.

1.Universidade Federal de Pernambuco - Programa de Pós-Graduação em Educação - Recife (PE), Brasil.

*Autora correspondente: alicebotler@gmail.com

Dossiê organizado por: Joyce Mary Adam e Débora Cristina Fonseca 


\section{Introdução}

A violência, em todas as suas formas, é tema já bastante debatido entre pesquisadores da educação, especialmente quando se foca nos jovens. Neste artigo, chamamos a atenção para algumas distinções conceituais que ocupam nosso olhar a esse respeito e nos estimulam a avançar a partir daí.

Um primeiro aspecto diz respeito ao aumento nos índices de violência, especialmente homicídios, entre jovens: tais indicadores não incluíam, até pouco tempo, as formas de violência nas escolas, mas passaram, recentemente, a integrar massivamente estupros, assassinatos e outros tipos de violência registrados dentro de escolas, visibilizados agora pela mídia.

Um segundo aspecto que mobiliza a reflexão é a ampliação da ação dos movimentos sociais, impulsionados pela Internet, o que vem gerando redes de indignação e de esperança (CASTELLS, 2013), potencializando laços de solidariedade, por um lado, mas gerando também terror e terrorismo, constrangendo e amedrontando as pessoas. Em ambos os casos, os jovens são os maiores protagonistas, e também os maiores alvos.

A questão da justiça constitui um terceiro aspecto, que interessa esclarecer. Os debates recentes vêm relacionando justiça à ideia de direito à escola de qualidade para todos. Tal direito é fundado, especialmente, no âmbito do acesso pela via jurídica formal, em detrimento de trabalhos que realcem as práticas assumidas no cotidiano escolar, as quais permitem efetivar o Direito, o que conduz nossa curiosidade para o âmbito da micropolítica e da microssociologia, com foco nos sentimentos de injustiças sofridas.

Da vivência desses aspectos, brotam nos jovens hoje as diferentes vivências de cidadania, por meio das quais sentimentos difusos se confundem, ora tendendo à valorização do princípio individualista, ora ao princípio coletivista, além de suscitarem contradições relativas a práticas e discursos, que pendulam entre uma abordagem liberal ou comunitarista de experiências no interior das escolas.

Para reduzir violências e conflitos nas escolas, procuramos analisar essas questões e alertar para práticas sociais, via recorte de pesquisa qualitativa com escolares de Brasil e Portugal. Apresentamos debate teórico e dados empíricos para aprofundar o tema.

\section{Juventudes e Violências nas Escolas}

Os estudos concebem o jovem ora como ser incompleto, imaturo, que precisa ser educado e preparado para vida adulta, ora como sujeito social, ser ativo, que produz sua própria cultura, bem como seu próprio modo de viver e interagir com o mundo (MARTINS; DAYRELL, 2013; AMARAL; FERREIRA, 2014). Tais autores concordam quanto à pluralidade das juventudes e suas particularidades, incluindo-se aí especificidades conforme classe social, gênero, nacionalidade e oportunidade escolar. Coadunam também quanto à ideia de que as juventudes não são ameaça; pelo contrário: relevam suas potencialidades, por meio das quais se valorizam a vida, a criatividade e a energia. Castells (2013, p. 10) acrescenta que a juventude na escola é o entrecruzamento de "emoção e cognição, trabalho e experiência, história pessoal e esperança no futuro".

Os jovens são ainda formuladores de cultura (AMARAL; FERREIRA, 2014, p. 217) e associados à retomada das dimensões pública e humana da intersubjetividade. Essa energia vibrante irradia, seja por via do espírito curioso, questionador, construtivo, seja por reações explosivas, críticas exacerbadas e autocentrismo, o que frequentemente se dá sob a forma de conflitos que, por vezes, resultam em violências. 
Reside aí um quarto aspecto a ser esclarecido, que acrescentamos aos três mencionados na introdução deste artigo: conflitos são fruto de posições distintas, o que é típico da democracia saudável. Nas escolas, no entanto, são frequentemente tomados como indisciplinas, as quais, por sua vez, são consideradas quebra de regras, o que só faz sentido se essas últimas forem claras, explicitadas como necessárias à convivência naquele coletivo, algo que nem sempre ocorre. Já as violências são agressões que ultrapassam qualquer possibilidade de diálogo e exigem outros tratamentos, inclusive judiciais. Assim, para dar conta dos conflitos, o diálogo parece a melhor abordagem, enquanto, para reduzir as indisciplinas, o esclarecimento de regras é o melhor tratamento. A confusão entre esses conceitos vem gerando ações paliativas, após pequenos conflitos terem tomado grande vulto e explodirem como violências nas escolas.

Tal distinção auxilia a compreender o contexto que envolve as juventudes, as quais hesitam diante da tensão entre as demandas individuais e as sociais, entre o interesse nos bens privados e na felicidade individual, por um lado, e, por outro, no bem coletivo e referente às relações sociais. A distinção é necessária para examinar o tema das juventudes diante das violências nas escolas. Trata-se de princípios basilares que guiam as ações e norteiam os formatos assumidos pelos conflitos, configurando-se como agressivos ou argumentativos, de natureza interpessoal ou intrapessoal.

Tal tensão manifesta, inclusive, a percepção que os jovens têm sobre a democracia. A crítica da juventude à democracia e a qualquer forma de opressão (incluindo a hierarquia na relação professoraluno) indica que ela reconhece sua existência, bem como tem o propósito de estabelecer seus limites. Nem sempre se percebe, é verdade, um pensamento amadurecido; pelo contrário: sua forma de reflexão é, por vezes, ingênua, imediatista e autocentrada, o que exige um trabalho educativo.

Amaral e Ferreira esclarecem que a crítica dos jovens à democracia emerge via demandas por mudanças "nos campos da experiência, dos relacionamentos e da comunicação" (2014, p. 221), fortalecendo a ideia de campo de relações, o que leva a mudanças nos planos do conhecimento e da experiência. Compreender as juventudes e suas manifestações requer aprofundamento dos diversos sentidos da democracia, bem como compreendê-la na perspectiva de que a "violência tornou-se o fermento da inquietação cotidiana" (COSTA, 1986, p. 9).

\section{Democracia e Justiça}

Tomamos a ideia da democracia não apenas do ponto de vista formal, do direito adquirido, mas, sobretudo, do ponto de vista social, do direito experimentado. Evidentemente, a democracia reflete a tensão entre a busca dos laços de sociedade e a busca da felicidade individual e do favorecimento de uma vida privada. Isso acarreta uma multiplicidade de demandas, tornando os cidadãos indiferentes ao bem público e desviando suas energias da cena política para o sucesso material. Tal tensão reflete certo posicionamento valorativo, tendendo a privilegiar a alteridade ou individualidade, a defesa de direitos individuais ou coletivos. A valoração se consolida em juízos, que materializam a ideia de justiça e aquilo que se entende por justo, razoável, procedente, em termos de condução das ações.

Rancière explica a relação entre democracia e justiça com base nos princípios que as sustentam, mais do que nas formas encontradas de sua expressão: “[...] a palavra democracia não designa propriamente nem uma forma de sociedade, nem uma forma de governo. A sociedade democrática é apenas uma pintura fantasiosa, destinada a sustentar tal ou qual princípio do bom governo" (2014, p. 68).

O juízo de valor relaciona, por exemplo, a ideologia republicana com a potencialidade da legislação, ou como aquela que: 
exige a estrita delimitação das esferas do político e do social e identifica a república com o reino da lei, indiferente a todas as particularidades. Foi assim que ela argumentou sua discussão sobre a reforma escolar nos anos 1980. Propagou a simples doutrina de uma escola republicana e laica, que distribui a todos o mesmo saber sem considerar diferenças sociais. Estabeleceu como dogma republicano a separação entre a instrução, isto é, a transmissão dos saberes, que é assunto público, e a educação, que é privado (RANCIÈRE, 2014, p. 81).

A crítica incide na distinção entre a aparência democrática e sua essência vivida, seus pressupostos fundamentais, o que leva a compreender que a responsabilidade pela educação numa sociedade democrática é de todos (Estado e sociedade), o que leva a ligar democracia e justiça.

Lima e Gandim (2017) reforçam essa ligação quando exploram o problema do ponto de vista da justiça social, compreendendo-a como relacional, que envolve vínculos de poder e de conexão social, englobando a relação entre estrutura e sujeito. Os autores associam justiça social às transformações contemporâneas no âmbito educacional, o qual aproxima educação e mercado, criticando a privatização dos sistemas públicos de ensino como dominação e reprodução social. A democratização pela via da privatização recairia, então, na homogeneização do ensino, docilizando os estudantes como uma massa.

Em contrapartida, os autores apresentam o modelo de conexão social, cujo objetivo político é democratizante, cabendo aos diferentes segmentos sociais a retificação da injustiça social, por meio da localização de soluções e da criação de ações que busquem maior justiça social em cada contexto. Democracia e justiça, assim, são conectadas por meio da responsabilização coletiva pela educação e pelo reconhecimento do outro.

Derouet (2002) aponta para um universo de justificação múltipla, considerando as diferentes lógicas dos diferentes mundos em que cada um vive. Em lógica semelhante, Estêvão (2015) relaciona a pluridimensionalidade da justiça com a questão democrática a partir dos princípios que dão sustentação aos diversos mundos (cívico, doméstico, gerencialista) e caracteriza a contemporaneidade por seus fundamentalismos, com destaque para o fundamentalismo de mercado, que impacta questões como direitos humanos, justiça social e educação.

Esse raciocínio se reverte em competitividade, meritocracia, individualismo e privatismo, inclusive como critérios de justiça nos processos de escolarização. A democracia, na lógica mercadológica, portanto, reflete não apenas poder e privilégios, mas principalmente, certa racionalidade e justificações das ações, o que limita o potencial de emancipação. Assim, a cultura escolar, ainda que se expresse na valorização das diferenças, cultiva o individualismo, pautando-se no argumento da neutralidade da justiça formal/legal. Por isso, interessa-nos analisar a justiça do ponto de vista das práticas.

Práticas justas resguardam princípios de acesso, permanência e adequadas condições de trabalho, bem como incluem justificativas não universais, tampouco neutras, mas relativas ao bem da comunidade, respeitando sua cultura. Práticas justas tomam como base as diferenças e desigualdades entre as pessoas e, a partir daí, encaminham a distribuição, com vistas a tornar a sociedade mais justa (SIQUEIRA, 2017). Consideram aspectos culturais, contexto e história do local em que se pratica justiça, coadunando com a noção de igualdade complexa.

A justiça é, portanto, local e vivida de maneira fiel às compreensões partilhadas dos seus membros. A teoria pluralista da justiça social é baseada na igualdade complexa, que abarca uma diversidade de procedimentos e critérios conforme o significado do bem social em causa (WALZER, 2003). Tal autor 
argumenta a favor de um horizonte de valores comunitariamente compartilhados, para que se decida sobre questões de justiça como um referencial estipulado em dada comunidade. Defende a sociedade igualitária de modo complexo, na qual a educação seria uma das esferas da justiça; entende que a igualdade gere desigualdades e que a justiça distributiva gere conflitos sociais. Busca conciliar a universalidade com a diversidade, de maneira que alguns princípios devam ser partilhados e que conflitos sejam vistos como inerentes.

Nesses termos, justiça é atribuição crítica de valores; é composta por princípios de igualdade e equidade; e articula-se com outros valores morais, como dignidade, respeito, diálogo.

Conforme Menin et al. (2013), o princípio da igualdade é fundamental na justiça distributiva, para estabelecer critérios de atribuição de direitos e de deveres entre todas as pessoas. O mesmo ocorre na justiça retributiva, em relação à atribuição de penalidades aos atos injustos, desrespeitosos e relativos às infrações. A justiça comutativa se centra num acordo voluntário, no contrato e no intercâmbio entre iguais, implicando certa autonomia moral. Na prática, no entanto, ressalva-se que a moralidade é questionável e que, nem sempre, a democracia alcança a obtenção de acordo ou consenso, gerando o sentimento de injustiça.

\section{Democracia e Injustiças}

O sentimento de injustiça decorre de embates entre posições distintas, o que pode ser observado nas práticas escolares como indisciplinas, conflitos e violências. Quando problematizado, isso potencializa a expressão de suas motivações e, supostamente, a obtenção do consenso para a recomposição de relações harmoniosas e civilizadas.

Esse aspecto encaminha-nos para a ideia de que a ampliação dos conflitos e de suas derivações nas escolas seja concernente à ausência dessa problematização e à naturalização das injustiças ali experimentadas, num ambiente onde não se estimulam laços de solidariedade e cooperação, indispensáveis à democracia.

A ausência de diálogo leva, portanto, a extremos, já que não se escuta o outro, tal como esclarece $\mathrm{Oz}$ (2017) quando trata do fanatismo, tomado como universo de dualidades excludentes. Fanáticos "vivem num mundo em preto e branco", manifestando certo dogmatismo inflexível.

O fanático é "conformista, caminha cegamente por um rumo preestabelecido, é obediente sem pensar nem objetar, anseia pertencer a um grupo humano compacto e sólido", cultuando a personificação de um líder (OZ, 2017, p. 24-25) e abdicando de sua individualidade. Busca uma referência a seguir ou constitui, em si mesmo, uma liderança. A ideia de fanatismo auxilia a compreender as relações estabelecidas no universo escolar, em que brincadeiras de mau gosto são praticadas entre colegas, expondo características de forma grosseira e preconceituosa, reduzindo o outro e ultrapassando limites de respeito. O que define o fanático não é o volume de sua voz, mas sua tolerância.

Trata-se da imposição de ideias e valores sem suportar qualquer diferença, seja de opinião, seja na maneira de ser e de agir no mundo. Ora, discordar é saudável e faz parte da democracia, mas decretar uma imposição sobre os demais é autoritarismo, e todo ser humano é capaz de discernir uma divergência de opiniões daquilo que constitui algo imoral em termos de tratamento dado ao outro.

Queremos dizer com isso que a ausência de uma experiencia escolar dialógica pode levar sujeitos a extremos, justamente em virtude da impossibilidade de argumentação. Essa poderia, a nosso ver, auxiliar na implementação de novos sentidos às práticas, a partir da troca de campos de visão, o que geraria compreensão do ponto de vista do outro, ampliando a potencialidade de obtenção de consensos. Quando isso não acontece, aflora o sentimento de injustiça sofrida. 
Tratamos aqui da qualidade da permanência na escola, incluindo a formação para o diálogo consistente, do qual deriva a possibilidade de cada um ser escutado. A qualidade da permanência incide na autopercepção do aluno de sua condição de civilidade, em oposição à condição de fracasso, baixa autoestima e recusa à escola. Gera a identificação do aluno com um ambiente escolar que se percebe como justo.

Do contrário, o sentimento de injustiça se relaciona às desigualdades, à redistribuição, à falta de reconhecimento e ao desrespeito (DUBET, 2004; DEROUET, 2002). Os sentidos atribuídos pelos jovens à experiância escolar denotam a tensão presente nas suas relações com os processos de escolarização, com reflexo nas relações de poder da escola (MARTINS; DAYRELL, 2013).

Tais aspectos nos conduzem a relacionar os jovens à escola, com foco nas motivações que os levam a praticar violências, mas em busca de alternativas para sua redução. Partimos da suposição de que a formação para a atitude justa é necessariamente reflexiva e crítica, por meio da aprendizagem sobre práticas vividas, que se consolidam como referenciais valorativos, pautados em valores de alteridade, solidariedade e coletividade.

\section{Sentidos Atribuídos por Jovens Escolares à Justiça no Brasil e em Portugal}

A pesquisa qualitativa, do tipo estudo de casos, contrastou juventudes distintas, em contextos, culturas, valores e experiências escolares diversas. A coleta de dados, em quatro realidades (no Brasil e em Portugal, em escolas de centro urbano e de periferia), sem intuito comparativo, analisou as concepções e práticas a respeito das violências e da justiça entre sujeitos escolares. Um dos motivos para o aumento da violência juvenil seria o sentimento de injustiça na escola, causado pela precariedade na compreensão das regras que regem o universo escolar, capaz de gerar situações de insatisfação que podem ocasionar indisciplinas e/ou violências, além, é claro de outros fatores.

A análise de conteúdo temático-categorial foi organizada de modo a criarmos unidades temáticas, que geraram categorias e subcategorias de análise, com base num roteiro semiestruturado de entrevista. As entrevistas ocorreram no ambiente escolar natural, em horários de intervalo, e com estudantes de Ensino Médio que aderiram espontaneamente, totalizando 67 sujeitos, sendo 30 brasileiros (19 da escola de centro e 11 da de periferia) e 37 portugueses (18 da escola de centro e 19 da de periferia). Os cuidados éticos de responsabilização e preservação de sigilo foram tomados. Além disso, os pais ou responsáveis assinaram termos de consentimento e os sujeitos foram identificados por siglas, a saber: EM ou EF para estudante masculino ou feminino, seguido de numeração, e EC ou EP para Escola de Centro ou de Periferia, além de Br para Brasil e Pt para Portugal. Assim, por exemplo, denominamos EF5 EPBr para estudante do sexo feminino cuja numeração atribuída é 5 da escola de periferia no Brasil. Pelo mesmo motivo, utilizamos apenas as iniciais de nomes citados pelos entrevistados.

Ao serem questionados a respeito de sua concepção de escola justa, os estudantes brasileiros afirmaram:

(Tem) Uma estrutura boa (EF5 EPBr).

Não só estrutura, minha gente, os alunos também. Ter uma aula, a aula de DHC (Direitos Humanos e Cultura), quase nem têm aula de DHC. A aula é de passar vídeos pra gente ver, só que o pessoal não se interessa. Não se interessa mesmo pra ver os vídeos que A passa. Gente conversando lá atrás e, os que querem assistir não conseguem, porque os de trás ficam fazendo barulho (EF2 EPBr). 
A é um professor muito legal, mas tem outra professora daqui que saiu pra outra escola, uma escola técnica, ela não vinha muito aqui, mas, quando vinha, todos os alunos prestavam atenção, debatiam, falavam sua opinião sobre tudo (EF3 EPBr).

A concepção de escola justa revela, no diálogo, a ausência de interesse pelo tema explorado por um professor e a saída da professora reconhecida como interessante, aspectos que fazem parte do universo injusto de uma escola: o professor em exercício é fraco e a professora boa abandonou a escola por outra melhor. Ao tratarem da noção de escola justa, estudantes brasileiros apresentam suas críticas àquilo que entendem como injusto, a exemplo da infraestrutura. Os estudantes portugueses, por sua vez, afirmaram:

É um conceito totalmente utópico, mas acho que uma escola mais justa seria uma escola sem testes, por exemplo. Com avaliação, mas sem classificação. Aqui os alunos não querem aprender, eles querem ter notas! (EF5 ECPt)

Uma escola em que as pessoas sejam imparciais, que não diferenciem os alunos muitas vezes porque é filho de um amigo (EF4 ECPt).

Uma escola justa, acho que é um espaço onde não haja aquela indisciplina toda, pois não há professores estressados. Porque os professores andam estressados com os alunos malcomportados. E nós próprios, os colegas de turma, também ficamos um bocado estressados com eles. E acho que, se fôssemos justos com os professores, com os funcionários e vice-versa, na medida em que nos respeitássemos uns aos outros, acho que era muito mais fácil convivermos aqui e acho que seria mais fácil suportar a escola (EF1 ECPt).

A realidade portuguesa reverbera a ideia de não haver uma escola justa, bem como a crítica ao posicionamento dos próprios colegas, que não querem aprender. Ao mesmo tempo, tem sensibilidade para os professores estressados, que seriam, por isso mesmo, também injustiçados. A atitude dos colegas é vista como empecilho à experiencia de escola mais justa.

A escola justa é, assim, relacionada à crítica de estudantes brasileiros, que incide em objetivos imediatistas, os quais são contemplados como ponto de partida na rotina portuguesa; ou seja, brasileiros aspiram uma escola com bons professores, enquanto portugueses parecem já os ter. Portugueses, dessa maneira, parecem amadurecer em relação a aspectos comportamentais, bem como às relações interpessoais, numa perspectiva coletivista, já que algumas bases da escola justa já estão disponíveis em seu universo.

Quando o assunto é a concepção de injustiça, os estudantes das escolas brasileiras apontam exemplos ali vividos que denotam os princípios de igualdade e equidade:

É quando tem o pessoal da merenda, ele tem que distribuir uma certa quantidade pra todo mundo, mas, se uma pessoa passa uma certa dificuldade e não comeu hoje e ela quer repetir e não pode, porque a comida vai ser jogada no lixo, isso é uma injustiça que aconteceu com ela. É justiça dar pra todo mundo, mas quando a pessoa tá com mais fome e não pode comer porque não pode repetir, mesmo tendo comida, é uma injustiça! (EM12 ECBt)

Em diálogo entre estudantes portugueses da escola de periferia, colocam: 
Temos regras mais rígidas do que em outras escolas, somos mais controlados em termos de saídas, convivências, nos observam mais em termos de namoros também, supostamente não pode. Na escola, não (EF3 EPPt).

Há auxiliares, mas há também muitas câmeras de vigilância, sobretudo algumas mais escondidas (EF2 EPPt).

Acho que eles não ficam observando as câmeras, mas apenas se alguma coisa se passa. Assim, por exemplo, deixamos lá a mochila pousada e quando voltamos percebemos que faltam-nos as coisas. Assim, podemos perceber quem é quem. Se mexeram numa mochila, eles vão lá (nas imagens) observar o que se passou (EM1 EPPt).

Os extratos distinguem que, na EPPt, estudantes denotam um olhar mais conservador do ponto de vista da organização escolar, enquanto, no contexto escolar de centro, compreendem a experiência escolar de massa, numa perspectiva social abrangente. Na escola de periferia, assinalam que são mais vigiados. No Brasil, por sua vez, apreende-se que, na ECBr, há mais acesso à informação, melhor formação docente e um ensino mais qualificado, enquanto, na EPBr, observa-se certo sentimento de exclusão, abandono, falta de particularidades.

Observa-se certa consciência social mais crítica no universo português em relação aos jovens brasileiros no que concerne a princípios de justiça. Tais princípios aparecem na forma de críticas às desigualdades quanto a tratamentos dados a estudantes mais novos, tensionando o debate entre igualdade versus equidade, como mostra o diálogo abaixo, no tocante ao sentimento de injustiça:

Eu já [senti injustiça], porque eu queria imprimir aqui um trabalho [escolar] do negócio de empreendedorismo aqui e não deixaram eu sair (EF1 ECBr).

Não deixaram sair, que a gráfica é aqui do lado. Agora, se fosse um [aluno] do terceiro ano, pode. E a gente nem vai gazear, a bolsa tá aqui, a gente deixou tudo [na sala], até celular, se quiser, a gente deixa, mas eles não deixam [sair]. Agora, se fosse segundo ou terceiro ano, deixavam (EF3 ECBr).

O estudante português afirma:

Acho que os alunos mais velhos têm mais maturidade, já têm consciência, então (professores) afrouxam um pouquinho (as regras), facilitam mais um bocadinho, mas os menores têm que ter mais rigor, é mais restrito. Confiam mais em nós (EM1 EPPt).

Reparamos os diferentes princípios que regem a crítica estudantil à desigualdade no tratamento dado pela escola nos extratos acima: brasileiros são tomados pelo ponto de vista individual, enquanto portugueses compreendem as práticas escolares do ponto de vista coletivo. Tratamentos distintos são dados em escolas de ambos os países, mas a organização escolar coletiva parece mais clara para portugueses do que para brasileiros.

Ao indagarmos a respeito de seu entendimento sobre as violências na escola, bem como se já haviam presenciado situações violentas com colegas no contexto escolar, estudantes brasileiros afirmam que essas fazem parte do universo natural da escola: 
Eu já fiz violência verbal com ela, a gente sofre e pratica. É negócio inocente, só..., tipo..., aqui minha amiga! Aí quando é outra pessoa que vem falar de mim, aí é outra situação que não fica legal. Digamos que eu tenho certas rixas por aí, mas violência, violência, eu não sofro não, só pratico. É verbal, viu? Tenho alvo fácil [olha pra aluna 4] (EF 2 ECBr).

Estudantes portugueses relacionam violências à responsabilidade familiar:

Educação que os pais não sabem dar aos filhos. Existem pessoas diferentes e, muitas vezes, não sabem lidar com essas diferenças. E, muitas vezes, existe violência por causa das preferências sexuais de alguém. Por causa de serem homossexuais. As pessoas não sabem lidar muito bem com isso (EF2 EPPt).

Eu já presenciei duas discussões que ficaram violentas e começaram mesmo a dar murro, lá na cantina (EF2 ECPt).

Os dados denotam que estudantes brasileiros sentem um misto de orgulho e vergonha por conta das violências nas escolas, já que as tomam como parte da brincadeira, mas, ao mesmo tempo, reconhecem que oprimem, o que precisaria ser dito e esclarecido. Os estudantes portugueses relatam que violências não fazem parte da rotina, mas que, eventualmente, ocorre algum caso de briga mais violenta e, imediatamente, aparece alguém da equipe escolar para apartar.

Escolas portuguesas têm câmeras de vídeo e mais funcionários que as brasileiras. Estudantes brasileiros reclamam das diferentes oportunidades de aprendizagem em laboratórios de informática, por exemplo, cuja capacidade é limitada, bem como da regra de que, mesmo quando sobra comida, não se permite àqueles que passam fome repetir.

\section{Considerações Finais: Juventude e Escola com Perspectivas de Futuro}

O artigo analisou a relação entre juventudes e escola, com ênfase nos princípios de justiça, e teve a intenção de alertar para práticas sociais visando à redução das violências e demais conflitos nas escolas, por meio do universo valorativo e relacional de estudantes do Ensino Médio.

Os dados mostram que, entre as motivações que levam escolares a cometerem atitudes violentas, está o sentimento de injustiça, fortemente associado, por estudantes brasileiros, a aspectos individuais, denotando perspectiva autocentrada e imediatista das práticas escolares, compreensão restrita da realidade social e, acrescentamos, abordagem fundada em princípios liberais de justiça. Entre os estudantes portugueses investigados, apreenderam-se o sentimento de injustiça associado a aspectos sociais coletivos e a compreensão ampliada da realidade social, em que tensões entre as demandas individuais e coletivas são minimizadas diante de práticas escolares fundadas em princípios comunitaristas de justiça.

Sem a pretensão de generalizar resultados comparativamente, os dados trazem a ideia de uma escola mais justa, como espaço de criação e aprendizagem de valores e competências, fruto e produtor de seu lugar no âmbito das desigualdades sociais. As diversas concepções de justiça revelam práticas escolares baseadas em princípios socializadores, em que a tensão entre igualdade e diferença é vista como dilema a enfrentar, o que auxilia estudantes a questionarem seus próprios juízos de valor e impulsos, 
potencializando a canalização de sua energia por meio de objetivos, a exemplo da crítica amadurecida dos estudantes portugueses referente à vigilância nas escolas.

A justiça deve ser capaz de produzir segurança e bem-estar, bem como socialização voltada para o contexto e pautada no diálogo, além de levar em conta as necessidades e tradições locais. Ela vai além do conflito por direitos individuais, buscando suas origens e as necessidades que dele surgiram, tornando, assim, a escola um lugar propício para resolver conflitos de maneira não violenta por meio de diálogo, sensibilização e transformação, com vistas a reduzir violências e gerar relações de empatia e respeito.

\section{Financiamento}

Conselho Nacional de Desenvolvimento Científico e Tecnológico

[https://doi.org/10.13039/501100003593]

Processo \# 444.372/2014-8.

\section{REFERÊNCIAS}

AMARAL, M. G. T.; FERREIRA, T L. A primavera juvenil no Brasil e no mundo: O "senso de possibilidade" e o sentido da "pós-história" em jogo no aprofundamento do sentido da democracia. Publ. UEPG Ciências Sociais Aplicadas, Ponta Grossa, v. 22, n. 2, p. 215-228, jul.-dez. 2014. https://doi.org/10.5212/PublicatioCi. Soc.v.22i2.0008

CASTELLS, M. Redes de indignação e esperança: Movimentos sociais na era da internet. Trad. Carlos Alberto Medeiros. Rio de Janeiro: Zahar, 2013.

COSTA, J. F. Violência e psicanálise. Rio de Janeiro: Graal, 1986.

MARTINS, F; DAYRELL, J. Juventude e participação: O grêmio estudantil como espaço educativo. Educação \& Realidade, Porto Alegre, v. 38, n. 4, p. 1267-1282, out.-dez. 2013. https://doi.org/10.1590/ S2175-62362013000400014

DEROUET, J-L. A sociologia das desigualdades em educação posta à prova pela segunda explosão escolar: deslocamento dos questionamentos e reinício da crítica. Revista Brasileira de Educação, n. 21, set.-dez. 2002. https://doi.org/10.1590/S1413-24782002000300002

DUBET, F. O que é uma escola justa? Cadernos de Pesquisa, v. 34, n. 123, p. 539-555, set.-dez. 2004. https:// doi.org/10.1590/S0100-15742004000300002

ESTÊVÃO, C. V. Tempos anormais e novas fantasias. Novas tendências em direitos humanos, justiça e educação. Revista Portuguesa de Educação, v. 28, n. 2, Braga, jun. 2015. https://doi.org/10.21814/rpe.7730

LIMA, I. G.; GANDIM, L. A. Justiça social na educação: Pressupostos e desdobramentos práticos. Práxis

Educativa, Ponta Grossa, v. 12, n. 3, p. 929-941, set.-dez. 2017. https://doi.org/10.5212/PraxEduc.v.12i3.013 
MENIN, M. S. S.; BATAGLIA, P. U. R.; MORO, A. Adesão ao valor justiça em crianças e adolescentes. Estudos em Avaliação Educacional, São Paulo, v. 24, n. 56, p. 18-47, set.-dez. 2013. https://doi.org/10.18222/ eae245620132733

OZ, A. Mais de uma luz: Fanatismo, fé e convivência no século XXI. São Paulo: Companhia das Letras, 2017.

RANCIÉRE, J. O ódio à democracia. São Paulo: Boitempo, 2014.

RANCIÉRE, J. O mestre ignorante. Cinco lições sobre a emancipação intelectual. Belo Horizonte: Autêntica, 2015.

SIQUEIRA, J. N. C. Contribuições da gestão escolar democrática nas concepções de democracia e justiça de estudantes. 2017. Dissertação (Mestrado em Educação) - Faculdade de Educação, Universidade Federal de Pernambuco, Recife, 2017.

WALZER, M. Esferas da justiça: Uma defesa do pluralismo e da igualdade. São Paulo: Martins Fontes, 2003.

Recebido: 01 Mar 2019

Aceito: 17 Set 2019

Comitê Editorial do Cedes/Coordenação deste número:

Izabel Galvão e Maria Rosa Camargo 